УДК 330.35

\title{
ИНДИКАТОРЫ УСТОЙЧИВОГО ЭКОНОМИЧЕСКОГО РАЗВИТИЯ: МЕТОДЫ И АЛГОРИТМЫ ИСПОЛЬЗОВАНИЯ
}

\section{Стрижакова Екатерина Никитична}

доктор экономических наук, профессор кафедры «Производственный менеджмент»

Стрижаков Дмитрий Валерьевич

кандидат экономических наук, доцент кафедры «Производственный менеджмент» Брянский государственный технический университет

\begin{abstract}
Аннотация: Для оценки устойчивого развития необходимо применять показатели, которые отражают все три его составляющие: экономическую, экологическую и социальную. В настоящее время единого индикатора не существует, однако все большее распространение получает показатель истинных сбережений. В статье приведены основные значения ключевых показателей, формирующих значение указанного индикатора для Российской Федерации в сопоставлении с другими странами, а также в динамике за последние двенадцать лет.
\end{abstract}

Ключевые слова: устойчивое развитие, индикатор, истинные накопления, экономический рост, ресурс, сбережения.

\section{INDICATORS OF SUSTAINABLE ECONOMIC DEVELOPMENT: METHODS AND ALGORITHMS}

\section{Strizhakov Dmitry Valerievich Strizhakova Ekaterina Nikitichna}

\begin{abstract}
It is necessary to apply indicators that reflect all three components of sustainable development: economic, environmental and social to evaluate it. There is no universal index, however, the indicator of true savings is becoming more widespread. The article presents the main values of the key indicators that form the value of this index for the Russian Federation in comparison with other countries, as well as in dynamics over the past twelve years.

Key words: sustainable development, indicator, genuine savings, economic growth, resource, savings.
\end{abstract}


Оценка устойчивого развития, его темпов и скорости требует использования новых индикаторов. Невозможно применять для этой цели стандартные макроэкономические показатели оценки экономического роста ВВП, ВНП, ЧНП. Главным их недостатком считается отсутствие информации о затратах природного капитала и разрушении экологических экосистем, которые произошли в процессе достижения определенных темпов экономического роста. Необходимость создания показателей устойчивого развития была озвучена и зафиксирована еще в 1992 году на Конференции в «Повестке дня на $\mathrm{XXI}$ век»: «B целях создания надежной основы для принятия решений на всех уровнях и содействия облегчению саморегулируемой устойчивости комплексных экологических систем и систем развития необходимо разработать показатели устойчивого развития» [1].

В настоящее время есть два основных направления, в которых идет разработка показателей: создание единого комплексного интегрального показателя или создание системы частных индикаторов для отражения отдельных аспектов устойчивого развития. Разработкой показателей занимается значительное количество организаций:

- $\mathrm{OOH} \mathrm{-} \mathrm{Система} \mathrm{индикаторов} \mathrm{устойчивого} \mathrm{развития,} \mathrm{Система}$ интегрированных экологических и экономических счетов (Integrated Enviromental and Economic Accounting), Индекс человеческого развития (Human Development Index);

- Всемирный банк - Индекс скорректированных чистых накоплений;

- Организация экономического сотрудничества и развития - ОЭСР, Система экологических индикаторов);

- Европейский союз;

- Всемирный фонд дикой природы (WWF) - Экологический след (The Ecological Footprint) и Индекс «живой планеты» (Living Planet Index)).

Показателей устойчивого развития существует достаточно много, однако вопрос об их унификации остается открытым. На наш взгляд, достаточно интересным является индекс «истинных сбережений», поскольку он отражает техногенное воздействие на биоразнообразие по различным аспектам, а также показывает агрегированную величину - «скорректированные истинные сбережения (\% от ВНД)», которая позволяет сопоставлять страны между собой и проводить ретроспективный анализ [2]. В то же время, разделение показателя на показатели, характеризующие сельское хозяйство; леса и биоразнообразие; океаны; водоснабжение и санитарию; окружающую среду и здоровье, дает 
возможность оценить динамику изменений по каждому из направлений сохранения окружающей среды.

Показатель «истинных накоплений (сбережений)» (genuine savings) был предложен в 1993 году Д. Пирсом и Дж. Аткинсоном. В настоящее время в публикациях Всемирного банка преимущественно используется название «скорректированные чистые накопления» (adjusted net savings). Расчет данного показателя происходит по следующему алгоритму [3]:

$$
\mathrm{GS}=\mathrm{GNS}-\mathrm{Dh}+\mathrm{CSE}-\mathrm{Dp}-\mathrm{CD}-\mathrm{PD},
$$

где GNS - валовые внутренние сбережения,

$\mathrm{Dh}$ - обесценение основного капитала,

$\mathrm{Dp}$ - истощение природных ресурсов,

CSE - текущие расходы на образование,

$\mathrm{CD}$ - ущерб от выбросов $\mathrm{CO}_{2}$,

$\mathrm{PD}$ - ущерб от выбросов твердых взвешенных частиц, диаметром меньше 10 микрон (РM10).

Истощение невозобновляемых природных ресурсов (Dp) определяется как отношение приведенной стоимости ренты, дисконтированной по процентной ставке $\mathrm{r}$, к периоду исчерпания природного ресурса. Для каждого вида невозобновляемых ресурсов природная рента $\mathrm{R}$ рассчитывается по странам мира как [3]:

$$
\mathrm{R}=(\mathrm{P}-\mathrm{C}) \cdot \mathrm{Q},
$$

где $\mathrm{P}$ - цена природного ресурса на мировом рынке,

C - средние затраты на добычу ресурса в стране,

$\mathrm{Q}$ - объем добычи природного ресурса.

В таблице представлена информация, использованная для расчета показателя «истинных сбережений» Российской Федерации в 2005 - 2017 гг.

Интересно проанализировать динамику изменения показателя «истинных сбережений» для Российской Федерации. Если в 2005 году значение показателя было равным -10,7\%, в 2010 году показатель стал принимать положительное значение, равное 1,5\%, а к 2017 году он уже возрос до 9,0\% валового национального дохода.

По экономической составляющей Российская Федерация показывает значения, которые характерны для группы стран с доходами, выше среднего уровня, величина ВВП на душу населения для РФ составляла 11720 долл., для группы указанной группы стран - 8263 долл; для стран Европы и центральной Азии - 24275 долл.; а в группе с высоким уровнем доходов указанный 
показатель принимал значение, равное 41932 долл. Величина скорректированного национального дохода на душу населения для Российской Федерации в 2017 году составляла 7315 долл., для группы стран с доходами, выше среднего уровня - 6302, для Группа Европа и центральная Азия - 18328 долл., а для стран с высоким уровнем дохода - 33452 долл.

Ущерб, причиняемый экологии, в Российской Федерации за анализируемые 12 лет несколько сократился. Величина лесной площади несколько уменьшилась с 50,4\% в 2005 году до 49,8\% в 2017 году; однако увеличилась площадь охраняемых территорий с 7,8\% до 11,4\% за оцениваемый период. Значительно сократилось число исчезающих животных, птиц, рыб и растений, так, в 2005 году количество исчезающих млекопитающих было равно 45, а в 2017 году значение данного показателя стало равным 32. Общий объем рыболовства возрос с 3718 тыс. тонн в 2005 году до 4617 тыс. тонн в 2017 году, однако и рост аквакультуры также происходил, в 2017 году значение показателя стало равным 4,7\%. Потребление энергии и величина $\mathrm{CO} 2$ на душу населения постепенно растет, что, конечно, является негативной тенденцией, расход электроэнергии также увеличивается, причем в сопоставлении со группами стран Европы и центральной Азии и стран с доходами выше среднего, значение показателя для Российской Федерации оказывается неоправданно высоким: в 2017 году значение указанного показателя для нашей страны составляло 6603 кВт-ч на душу населения, а для указанных групп стран - 5369 кВт-ч и 3495 кВт-ч соответственно. Ущерб, причиняемый населению от выбросов $\mathrm{CO}_{2}$, увеличился с 2,8\% до 3,9\% за прошедшие 12 лет, и, более того, он значительно превышает показатели для анализируемых групп стран, для стран Европы и Азии величина ущерба составляет 1,0\% от ВНП, а по группе стран с доходами выше среднего этот показатель равен 2,6\% в 2017 году. Однако при этом количество взвешенных частиц, оказывающих негативное воздействие на здоровье городского населения в Российской Федерации, значительно сократилась - с 26 мг/ м.куб в 2005 году до 17 мг/ м.куб в 2017 году.

Величина водоснабжения в Российской Федерации практически не изменилась за прошедшие 12 лет, однако процент пресной волы уменьшился с $1,8 \%$ в 2005 году до $1,4 \%$ в 2017 году.

В рамках географической группы стран Европы и центральной Азии положение Российской Федерации выглядит лучше по валовым внутренним сбережениям. В свою очередь, по этой группе, Российская Федерация выглядит 
хуже по потреблению основного капитала, по расходам на образование, истощению энергетических ресурсов (хотя данный показатель за 12 лет удалось снизить в 6 раз), истощению минеральных ресурсов, ущербу от выбросов углекислого газа, ущербу от иных загрязнений. По итогам, скорректированные истинные сбережения Российской Федерации меньше, чем в среднем по группе стран Европы и центральной Азии $(9,5 \%)$, и значительно меньше, по группе стран с доходами выше среднего уровня $(17,2 \%)$.

В рамках группы стран с доходами выше среднего уровня Российская Федерация выглядит лучше по расходам на образование. По всем остальным показателям Российская Федерация уступает средним значениям по группе. Итоговый скорректированные истинные сбережения по группе в два раза выше, чем в России. Однако в целом следует отметить положительную динамику скорректированных сбережений Российской Федерации, которые от отрицательных значений в 2005 г. достигли значения практически соответствующего среднему для группы стран Европы и центральной Азии.

\section{Список литературы}

1. Преобразование нашего мира: Повестка дня в области устойчивого развития на период до 2030 года [Электронный ресурс]. - Режим доступа: https://www.un.org/sustainabledevelopment/ru/about/development-agenda/ (дата обращения: 24.03.2021)

2. Стрижакова Е.Н., Стрижаков Д.В. Концепция устойчивого развития: история и современность // Менеджмент в России и за рубежом. 2020. № 6. С. 92-100.

3. Hamilton K. Genuine Saving as a Sustainability Indicator. The World Bank, 2000 [Электронный pecypc]. - Режим доступа: https://openknowledge. worldbank.org/bitstream/handle/10986/18301/multi0page.pdf?sequence=1\&isAllowe $\mathrm{d}=\mathrm{y}$

4. The Little Green Data Book 2005 [Электронный ресурс]. - Режим доступа: https://openknowledge.worldbank.org/bitstream/handle/10986/12428/ 34396.pdf?sequence $=1$ \&is Allowed $=\mathrm{y}$

5. The Little Green Data Book 2017 [Электронный ресурс]. - Режим доступа: https://openknowledge.worldbank.org/bitstream/handle/10986/27466/9781 464810343.pdf? sequence $=2$ \&isAllowed $=y$ 